\title{
Study on Vaccination Efficacy against Avian Influenza in Rajshahi, Bangladesh
}

Md. Shofiqul Islam ${ }^{1}$, Md. Hemayatul Islam², Md. Jalal Uddin Sarder ${ }^{1}$, K. M. Mozaffor Hossain ${ }^{1}$, Md. Shofinur Rahman $^{3}$ and Mir Rowshan Akter ${ }^{4}$

1. Institute of Biological Sciences, University of Rajshahi, Rajshahi-6205, Bangladesh

2. Department of Veterinary and Animal Science, University of Rajshahi, Rajshahi-6205, Bangladesh

3. Youth Training Center, Naogaon-6520, Bangladesh

4. Department of Microbiology, Hajee Mohammad Danesh Science and Technology University, Dinajpur-5200, Bangladesh

\begin{abstract}
Vaccines are used in integrated control strategies to guard poultry against H5N1 high-pathogenicity avian influenza (AI). This study was to evaluate the efficacy of AI vaccine against AI in poultry. About 400 serum samples were collected from the selected 130 farms located at Rajshahi region, Bangladesh. The study was carried out from January, 2013 to January, 2015. The AI vaccine titres were compared in different breed of layer, environmental temperature, feed and egg production. Result showed that the value of titres (mean $\pm \mathrm{SD}$ ) in Hyline brown, Hyline white, Bovans white and Novogen white were $6.71 \pm 0.05,6.67 \pm 0.06,6.79 \pm$ 0.03 and $6.43 \pm 0.04$, respectively. The highest serum antibody titres were $6.61 \pm 0.24$ against $\mathrm{AI}$ antibody in $>26^{\circ} \mathrm{C}$ environment temperature. The highest and lowest serum antibody value of AI against feed brand (nutrient) were $7.75 \pm 0.08$ and $5.58 \pm 0.22$ for Aftab and Quality brand feed, respectively.
\end{abstract}

Key words: Avian influenza, titres, layer, environmental temperature and egg production.

\section{Introduction}

Presently, poultry meat and eggs provide the cheapest quality animal protein to millions of people. There are around 15 millions small, medium and large poultry farms in Bangladesh, and approximately 246 million poultry population provide yearly 5,400 million pieces of eggs and nearly $37 \%$ of total animal protein [1]. In Bangladesh, a country has a population density of $964 / \mathrm{km}^{2}$ and 257 million poultry [2, 3]. Virus H5N1 infection was first detected among poultry in 2007 . By the end of 2013, the country had reported 549 outbreaks among poultry according to the World Organization for Animal Health [4]. The first human case of $\mathrm{H} 5 \mathrm{~N} 1$ virus infection in Bangladesh was identified during 2008 [5]. The current Asian H5N1 highly pathogenic avian influenza (AI) virus has spread over Asia, Europe

Corresponding author: Md. Hemayatul Islam, Ph.D., research field: small animal reproductive disease. and Africa, as well as affects village and commercial chicken operations in many Southeast Asian countries. The major control strategy for highly pathogenic avian influenza (HPAI) outbreaks in poultry has traditionally been one of eradication, via movement restrictions, slaughter of affected and at-risk birds, and improving biosecurity at poultry facilities to prevent initial infection. However, within the poultry, including ducks and turkeys, and in wildlife species, particularly migrating birds, alternate control strategies must be considered, with vaccines likely to be a key component, which is widespread presence of the current Asian H5N1 virus in village. Effective vaccines that can prevent infection as well as disease and be used in a variety of avian species, are needed for field use.

Currently, available commercial vaccines for AI are killed oil-emulsion virus vaccines. They have mostly been used to control endemic low pathogenic avian influenza (LPAI) in chickens and turkeys, or HPAI 
outbreaks in Pakistan and Mexico [6-8]. The European Union has approved use of inactivated oil-emulsion vaccines for use in Italy, provided that they allow for differentiation of infected versus vaccinated birds [9]. Control of mildly pathogenic avian influenza (MPAI) in Mexico has been undertaken with both killed vaccines and recombinant fowl pox vaccines [8]. The aim of this study was to evaluate the level of antibodies titres against $\mathrm{AI}$ in layer chicken vaccinated with inactivated $\mathrm{H} 5 \mathrm{~N} 1$ and $\mathrm{H} 5 \mathrm{~N} 2$ vaccine under different breed, egg production, feed of layer and environmental temperature of farms.

\section{Materials and Methods}

The study was conducted at Rajshahi, Bangladesh from January, 2013 to January, 2015. The whole experimental design was to detect the haemagglutination inhibition (HI) titres of AI that was protect flock from $\mathrm{AI}$ infection, and AI vaccine titres were compared under different layer breed, egg production, feed of layer and environmental temperature of examined farms. Total 130 farms were selected from the 400 farms which had having similar management, then each of 50 layer farms was randomly chosen for both observational group and 30 for control group. The AI H5N1 virus vaccine (strain Re-6) manufactured by Merial in France and AI H5N2 virus vaccine (strain A/duck/Postdam/1402/86) manufactured by Intervet in Netherland were vaccinated at the 1st, 5th and 15th weeks (inject subcutaneously with $0.5 \mathrm{~mL}$ ). The titres were done at $21 \mathrm{~d}$ after each vaccination. The experimental layer breeds were Hyline brown, Hyline white, Bovans white and Novogen white. Feeds fed in farms were different in crude protein and energy level according to manufacturer (Quality Feeds Ltd., Dhaka; Nurish Bangladesh, Dhaka and Aftab Bohumukhi Farms Ltd., Dhaka). Environmental temperature were $\leq$ $20{ }^{\circ} \mathrm{C}, 20-26{ }^{\circ} \mathrm{C}$ and $\geq 26{ }^{\circ} \mathrm{C}$ and egg production were $0 \%$ (pullet), $70 \%-80 \%, 80 \%-90 \%$ and above $90 \%$.

\subsection{Preparation of Chicken Red Blood Cell (RBC) Suspension}

A total of $5 \mathrm{~mL}$ of chicken blood was collected aseptically in a disposable syringe containing $1 \mathrm{~mL}$ of sodium citrate ( $4 \%$ solution) as anticoagulant. The blood was centrifuged at $1,500 \mathrm{rpm}$ for $15 \mathrm{~min}$, and the plasma and buffy coat were removed with a pipette. After washing three times with phosphate buffered saline (PBS), 1\% suspension in PBS was prepared for HI test.

\subsection{Laboratory Test}

This study was conducted jointly by Paragon Laboratory, Dhaka, Central Disease Investigation Laboratory (CDIL), Dhaka and Institute of Biological Sciences, University of Rajshahi among 130 layer farms at Rajshahi region in Bangladesh. The selected farms were more resemble in housing, feed, hygiene and management. From each flock, three chickens (a total of 400 chickens where three chickens from each farm, and 10 from large flock) were randomly selected for blood collection. $1 \mathrm{~mL}$ of blood was collected aseptically from wing vein of each bird and allowed to clot. Then sera were separated and stored at $-20{ }^{\circ} \mathrm{C}$ until the $\mathrm{HI}$ test was carried out. The antigen (AI inactivated vaccine, $\mathrm{H} 5 \mathrm{~N} 1$ ) used in this study manufactured by Marial, Nanjing Animal Health Co. Ltd., China. HI test was performed to detect the antibodies against AI.

\subsection{HI Test}

$\mathrm{HI}$ test was done according to the procedure of OIE [10]. Briefly, two fold serial dilution of $25 \mu \mathrm{L}$ serum was made with PBS in V-bottomed micro titer plates (Nunc) up to the 10th well. $25 \mu \mathrm{L}$ of four haemagglutinating (HA) units of AI virus or antigen was added up to the 11th well. The plates were kept at room temperature for more than $30 \mathrm{~min}$ to fascinate antigen antibody reaction. Then, $50 \mu \mathrm{L}$ of $1 \%(\mathrm{v} / \mathrm{v})$ chicken RBC suspension was added to each well. The 11 th well contains antigen and RBCs as the positive 
control and the 12th well contains only RBCs as the negative control. After gentle mixing, the RBCs were allowed to settle at room temperature for $40 \mathrm{~min}$ and agglutination was assessed by tilting the plates. If the samples showed peculiar central button shaped, settle of RBCs were recorded as positive. The maximum dilution of each sample causing HI was considered as the end point, which was used to estimate the HI titres. The HI titres of each serum sample were expressed as reciprocal of the serum dilution.

\subsection{Statistical Analysis}

The seroprevalence of AI infection in relation to breed of layer, environmental temperature, feed and egg production was compared by means of $F$ test. A significant level of $P<0.05$ and $P<0.01$ was used.

\section{Results and Discussion}

3.1 Results of Prevalence of Antibodies against AI in Layer Chickens

HI test was evaluated with different factors, such as breed, egg production, feed of layer and environmental temperature of farms, to find specific immunity against AI. The average antibody level was shown in Table 1, with mean HI titres $\left(\log _{2}\right)$ of $7.67 \pm$ $0.07,7.33 \pm 0.07$ and $3.34 \pm 0.17$, respectively, in H5N1, H5N2 and control group of layer chicken.

\subsubsection{HI Titres in Different Breed}

Different breed of commercial layer chickens was also examined in detail. In Hyline brown, Hyline white, Bovans white and Novogen white groups, HI antibody titres varied from 5 to 7 and their respective percentages were $26.9 \%, 16.9 \%, 44 \%$ and $12.2 \%$, respectively (Table 2). The mean level of antibody titres was the highest $(7.69 \pm 0.86)$ in Hyline white, followed by $7.60 \pm 0.13$ in Novogen white and $7.25 \pm$ 0.07 in Hyline brown, while the lowest $(5.36 \pm 0.29)$ in Bovans white breeds of layer. The variation was due to genetic composition, management and methods of data collection.

\subsubsection{HI Titres in Different Egg Production}

When compared with egg production of layer farms, the antibody titres had no significance effects in egg production (Table 3). The mean titres value of antibody titres in relation with egg production were observed $6.47 \pm 0.20,6.57 \pm 0.61,7.19 \pm 0.28$ and $6.08 \pm 0.48$ and their seroprevalence were $63 \%, 10 \%$, $14.6 \%$ and $12.4 \%$ in pullet with egg production $0 \%$, layers with egg production $70 \%-80 \%, 80 \%-90 \%$ and $>90 \%$, respectively.

\subsubsection{HI Titres in Different Feed Brand}

AI titres level of nutrient (feeds) evaluated by HI test was shown in Table 4 . The prevalence of HI titres was $62 \%, 18 \%$ and $10 \%$ in Quality, Nurish and Afteb brand feed fed, respectively. The mean highest to the lowest level of antibody titres were $7.75 \pm 0.08,7.60 \pm$ 0.11 and $5.85 \pm 0.22$ in Afteb, Nurish and Quality brand feed in layer flock.

3.1.4 HI Titres in Different Environmental Temperature

The vaccine immunity had no significance effect with environmental temperature, but level of titres was different in various group of environmental temperature (Table 5). The seroprevalence was $43 \%, 46 \%$ and $11 \%$, and the mean $\mathrm{HI}$ titres was $6.61 \pm 0.24,6.49 \pm$ 0.24 and $6.47 \pm 0.50$ in environmental temperature < $20{ }^{\circ} \mathrm{C}, 20-26{ }^{\circ} \mathrm{C}$ and above $26{ }^{\circ} \mathrm{C}$ of the region, respectively.

Table 1 Distribution of HI titres s against AI in serum samples of layer chickens.

\begin{tabular}{lllll}
\hline Type of vaccines application & No. of observation & $\begin{array}{l}\text { HI titres }\left(\log _{2}\right) \\
(\text { mean } \pm \mathrm{SD})\end{array}$ & F value & Significance \\
\hline H5N1 strain vaccine & 50 & $7.67 \pm 0.07^{\mathrm{a}}$ & $* 37.663$ & $* * *$ \\
H5N2 strain vaccine & 50 & $7.33 \pm 0.07^{\mathrm{b}}$ & & \\
Control & 30 & $3.34 \pm 0.17^{\mathrm{c}}$ & & \\
\hline Total & 130 & $6.54 \pm 0.16$ &
\end{tabular}


Table 2 Distribution of $\mathrm{HI}$ titres against AI in serum samples of layer chickens in various breed.

\begin{tabular}{|c|c|c|c|c|c|}
\hline Breed & No. of observation & Seroprevalence & $\begin{array}{l}\text { HI titres }\left(\log _{2}\right) \\
(\text { mean } \pm \text { SD) }\end{array}$ & $F$ value & Significance \\
\hline Hyline brown & 35 & $26.9 \%$ & $7.25 \pm 0.07^{b}$ & \multirow{4}{*}{19.952} & \multirow{4}{*}{$* *$} \\
\hline Hyline white & 22 & $16.9 \%$ & $7.69 \pm 0.86^{b}$ & & \\
\hline Bovans white & 57 & $44.0 \%$ & $5.36 \pm 0.29^{\mathrm{a}}$ & & \\
\hline Novogen white & 16 & $12.2 \%$ & $7.60 \pm 0.13^{b}$ & & \\
\hline Total & 130 & $100 \%$ & $6.54 \pm 0.16$ & & \\
\hline
\end{tabular}

a,b Means bearing uncommon superscript differ significantly; ${ }^{* *}$ significantly different at $P<0.01$.

Table 3 Effect of egg production on the distribution of $\mathrm{HI}$ titres against $\mathrm{AI}$ in serum samples of layer chickens.

\begin{tabular}{lllllc}
\hline Egg production & No. of observation & Seroprevalence & $\begin{array}{l}\text { HI titres }\left(\log _{2}\right) \\
(\mathrm{mean} \pm \mathrm{SD})\end{array}$ & F value & Significance \\
\hline $0 \%$ (pullet) & 82 & $63.0 \%$ & $6.47 \pm 0.20$ & & NS \\
$70 \%-80 \%$ (layer) & 13 & $10.0 \%$ & $6.57 \pm 0.61$ & 1.129 & \\
$80 \%-90 \%$ (layer) & 19 & $14.6 \%$ & $7.19 \pm 0.28$ & & \\
Above $90 \%$ (layer) & 6 & $12.4 \%$ & $6.08 \pm 0.48$ & \\
\hline Total & 130 & $100 \%$ & $6.54 \pm 0.16$ & \\
\hline
\end{tabular}

NS: not significant $(P>0.05)$.

Table 4 Effect of nutrition (feed brand) on the distribution of HI titres against AI in serum samples of layer chickens.

\begin{tabular}{llllll}
\hline Feed & No. of observation & Seroprevalence & $\begin{array}{l}\text { HI titres }\left(\log _{2}\right) \\
(\text { mean } \pm \text { SD) }\end{array}$ & F value & Significance \\
\hline Quality & 81 & $62 \%$ & $5.85 \pm 0.22^{\mathrm{c}}$ & & $* *$ \\
Nourish & 23 & $18 \%$ & $7.60 \pm 0.11^{\mathrm{b}}$ & 18.789 & \\
Aftab & 26 & $20 \%$ & $7.75 \pm 0.08^{\mathrm{a}}$ & & \\
\hline Total & 130 & $100 \%$ & $6.54 \pm 0.16$ & & \\
\hline
\end{tabular}

${ }_{\mathrm{a}-\mathrm{c}}$ Means bearing uncommon superscript differ significantly; ${ }^{* *}$ significantly different at $P<0.01$.

Table 5 Effect of environmental temperature on the distribution of $\mathrm{HI}$ titres against AI in serum samples of layer chickens.

\begin{tabular}{llllll}
\hline Environmental temperature & No. of observation & Seroprevalence & $\begin{array}{l}\text { HI titres }\left(\log _{2}\right) \\
(\text { mean } \pm \text { SD) }\end{array}$ & $F$ value & Significance \\
\hline$<20{ }^{\circ} \mathrm{C}$ & 56 & $43.0 \%$ & $6.61 \pm 0.24$ & & NS \\
$20-26{ }^{\circ} \mathrm{C}$ & 60 & $46.0 \%$ & $6.49 \pm 0.24$ & 0.078 & \\
Above $26{ }^{\circ} \mathrm{C}$ & 14 & $11.0 \%$ & $6.47 \pm 0.50$ & & \\
\hline Total & 130 & $100 \%$ & $6.45 \pm 0.16$ & & \\
\hline
\end{tabular}

NS: not significant $(P>0.05)$.

\subsection{Discussions of Prevalence of Antibodies against AI in Layer Chickens}

Although depopulation programmes have been enforced in many parts, HPAI H5N1 outbreaks have been frequently reported since 2003 in some Asian countries, including China, Indonesia, Vietnam, Thailand and South Korea [11, 12]. It appears that the HPAI H5N1 infection becomes an endemic disease in Asia. Human infection and deaths caused by HPAI
$\mathrm{A}(\mathrm{H} 5 \mathrm{~N} 1)$ viruses in several countries [13], such as $\mathrm{A}(\mathrm{H} 9 \mathrm{~N} 2)$ virus in Bangladesh [14], $\mathrm{A}(\mathrm{H} 7 \mathrm{~N} 2)$, $\mathrm{A}(\mathrm{H} 7 \mathrm{~N} 9), \mathrm{A}(\mathrm{H} 9 \mathrm{~N} 2)$ and $\mathrm{A}(\mathrm{H} 10 \mathrm{~N} 8)$ viruses in China [15], reflect the persistent public health threat posed by different AI A virus subtypes. Subtype H5N1 virus remains endemic among poultry in Bangladesh, China, Egypt, Indonesia and Vietnam [16]. Due to the coexistence of both large-scale poultry farms and backyard-raised chickens, ducks and geese, it is very 
difficult to successfully conduct the protection of AI in these areas.

That is why vaccination against $\mathrm{AI}$ is encouraged in some Asian countries in conjunction with depopulation in the HPAI-infected farms in limited areas in campaigns against HPAI. In Bangladesh, a pilot project was undertaken for vaccination against HPAI with H5N1 and H5N2 in Gajipur region. Therefore, some selected layer chicken farms were vaccinated in Rajshai and evaluated it by titres level.

The authors also observed the variation in HI titres and their relation with breed, egg production, nutrition (feed) and environmental temperature. Earlier, Sun et al. [17] evaluated many farms by inactivated oil emulsion vaccines of subgroup H5, and gave satisfactory results, but HPAI outbreaks still occurred in some vaccinated flocks. Smith et al. [18] reported that the appearance of antigenic variants might be a major reason responsible for the failures of vaccination. The authors observed that immunity against AI vaccine varied due to strain, breed, egg production and environmental temperature.

\section{Conclusions}

The immunity level (HI titres against $\mathrm{AI}$ ) was better in H5N1 strain. The best titres level against AI serum were observed in Hyline white breed, layer with $70 \%-80 \%$ egg production, fed Aftab brand feed and at environmental temperature $20-26^{\circ} \mathrm{C}$.

\section{References}

[1] Government of the People's Republic of Bangladesh. 2013. "Bangladesh Economic Review 2013." Accessed October, 2014. http://www.mof.gov.bd/en/index.php? option $=$ com_content $\% 20 \&$ view $=$ article $\% 20 \& \% 20 \mathrm{id}=301$ $\% 20 \& \% 20$ Itend $=1$.

[2] Directorate General of Health Services Bangladesh. 2012. "The 2nd National Avian and Pandemic Influenza Preparedness and Response Plan, Bangladesh, 2009-2011." Accessed July 9, 2012. http://oldweb.dghs.gov.bd/bn/important-documents-softw are/category/7-2012-07-09-07-43-26? download=6:2nd-na tional-avian-and-pandemic-influenza-preparedness-and-r esponse-plan-bangladesh.
[3] Bangladesh Bureau of Statistics. 2011. "Population and Housing Census: Preliminary Results 2011.” Accessed December 20, 2011. http://www.bbs.gov.bd/WebTestApplication/userfiles/Im age/BBS/PHC2011Preliminary\%20Result.pdf.

[4] World Organization for Animal Health. 2013. "Update on Highly Pathogenic Avian Influenza in Animals (Type H5 and H7)." Follow-Up Report No. 43. Accessed January 27, 2013. http://www.oie.int/wahis_2/public\%5C. $\% 5$ Ctemp\%5Creports/en_fup_0000014568_20131223_1455 41.pdf.

[5] Brooks, W. A., Alamgir, A. S. M., Sultana, R., Islam, M. S., Rahman, M., Fry, A. M., Shu, B., Lindstrom, S., Nahar, K., Goswami, D., Haider, M. S., Nahar, S., Butler, E., Hancock, K., Donis, R. O., Davis, C. T., Zaman, R. U., Luby, S. P., Uyeki, T. M., and Rahman, M. 2009. "Avian Influenza Virus $\mathrm{A}(\mathrm{H} 5 \mathrm{~N} 1)$, Detected through Routine Surveillance, in Child, Bangladesh." Emerg. Infect. Dis. 15 (8): 1311-3.

[6] Halvorson, D. A. 2002. "The Control of H5 or H7 Mildly Pathogenic Avian Influenza: A Role for Inactivated Vaccine." Avian Pathology 31 (1): 5-12.

[7] Naeem, K. 1998. "The Avian Influenza H7N3 Outbreak in South Central Asia." In Proceedings of the 4th International Symposium on Avian Influenza, 31-5.

[8] Swayne, D. E., and Suarez, D. L. 2000. "Highly Pathogenic Avian Influenza." Rev. Sci. Tech. 19 (2): 463-82.

[9] Capua, I., Terregino, C., Cattoli, G., Mutinelli, F., and Rodriguez, J. F. 2002. "Development of a Differentiating Infected from Vaccinated Animals (DIVA) Strategy Using a Vaccine Containing Heterologous Neuraminidase for the Control of Avian Influenza." Avian Pathol. 32 (1): 47-55.

[10] Office International Des Epizooties (OIE). 2002. Manual of Standards for Diagnostic Tests and Vaccines, 4th ed.. Paris, France: OIE.

[11] Swayne, D. 2007. "Changing Face of Avian Influenza Ecology and Its Control: From Wild Birds to Poultry and Back Again." In Abstract of the 15th World Veterinary Poultry Congress, 98-104.

[12] Yu, K. 2007. "Avian Influenza in China.” In Abstract of the 15th World Veterinary Poultry Congress, 105-10.

[13] World Health Organization. 2014. "Cumulative Number of Confirmed Human Cases for Avian Influenza A(H5N1) Reported to WHO, 2003-2014." Accessed December 4, 2014. http://www.who.int/influenza/human_animal_ interface/EN_GIP_20141223CumulativeNumberH5N1ca ses.pdf?ua=1.

[14] International Centre for Diarrhoeal Disease Research (ICDDR). 2011. "Outbreak of Mild Respiratory Disease Caused by H5N1 and H9N2 Infections among Young 
Children in Dhaka, Bangladesh, 2011." Health and Science Bulletin 9 (2): 5-12.

[15] World Health Organization. 2014. "Influenza at the Human-Animal Interface.” Accessed January 24, 2014. http://www.who.int/influenza/human_animal_interface/In fluenza_Summary_IRA_HA_interface_24January14.pdf? ua $=11$.

[16] Food and Agriculture Organization of the United Nations, World Organization for Animal Health and World Health Organization. 2011. "FAO-OIE-WHO Technical Update: Current Evolution of Avian Influenza H5N1 Viruses." Accessed September 2011. http://www.who.int/influenza/human_animal_interface/tri
partite_notes_H5N1.pdf.

[17] Sun, S. H., Cui, Z. Z., Wang, J., and Wang, Z. L. 2009. "Protective Efficacy of Vaccination against Highly Pathogenic Avian Influenza Is Dramatically Suppressed by Early Infection of Chickens with Reticuloendotheliosis Virus." Avian Pathology 38 (1): 31-4.

[18] Smith, G. J. D., Fan, X. H., Wang, J., Li, K. S., Qin, K., Zhang, J. X., Vijaykrishna, D., Cheung, C. L., Huang, K., Rayner, J. M., Peiris, J. S. M., Chen, H., Webster, R. G., and Guan, Y. 2006. "Emergence and Predominance of an H5N1 Influenza Variant in China." Proc. Nat. Acad. Sci. 103 (45): 16936-41. 